University of Wollongong

Research Online

Faculty of Health and Behavioural Sciences -

Papers (Archive)

Faculty of Science, Medicine and Health

January 2010

\title{
Regulating the types of foods and beverages marketed to Australian children: how useful are food industry commitments?
}

L Hebden

Lesley King

NSW Centre for Overweight and Obesity, Uni of Syd

Bridget P. Kelly

University of Wollongong, bkelly@uow.edu.au

Kathy Chapman

The Cancer Council of NSW

Christine Innes-Hughes

Cancer Council NSW

See next page for additional authors

Follow this and additional works at: https://ro.uow.edu.au/hbspapers

Part of the Arts and Humanities Commons, Life Sciences Commons, Medicine and Health Sciences Commons, and the Social and Behavioral Sciences Commons

\section{Recommended Citation}

Hebden, L; King, Lesley; Kelly, Bridget P.; Chapman, Kathy; Innes-Hughes, Christine; and Gunatillaka, Nilakshi: Regulating the types of foods and beverages marketed to Australian children: how useful are food industry commitments? 2010, 258-266.

https://ro.uow.edu.au/hbspapers/572

Research Online is the open access institutional repository for the University of Wollongong. For further information contact the UOW Library: research-pubs@uow.edu.au 


\title{
Regulating the types of foods and beverages marketed to Australian children: how useful are food industry commitments?
}

\begin{abstract}
Aim: Any regulation of food marketing to children requires clear definitions of the types of foods considered inappropriate and subject to restrictions. The aim of this research was to examine the commitments made by signatory companies of the Australian Food and Grocery Council's Responsible Marketing to Children Initiative regarding the types of foods considered appropriate for marketing to children. Methods: Nutrient criteria developed by signatory food companies were examined by comparing (i) thresholds set for negative nutrients (saturated fats, added sugars and sodium) and total energy to two existing nutrient criteria: Healthy Kids Association and the National Heart Foundation Tick, and (ii) the types of foods considered appropriate for marketing to children, if applying companies' commitments or the product's nutrient profile using the Food Standards Australia and New Zealand nutrient profiling tool. Results: All five company-developed nutrient criteria examined specified higher thresholds for negative nutrients compared with existing criteria, and were more likely to report negative nutrients per serve rather than per $100 \mathrm{~g}$. When applying company commitments, $57 \%$ more energy-dense, nutrient-poor foods and beverages were considered appropriate for marketing to children, compared with nutrient profiling. Conclusion: Food industry commitments regarding the types of foods considered appropriate for marketing to children do not adequately restrict the marketing for energy-dense, nutrient-poor foods. It is recommended food manufacturers who commit to restricting their marketing of unhealthy foods to children use a standardised, independent nutrient profiling tool based on per $100 \mathrm{~g} / 100 \mathrm{~mL}$ to determine the appropriateness of foods and beverages for marketing to children.
\end{abstract}

\section{Keywords}

regulating, food, types, industry, commitments, foods, beverages, marketed, australian, children, useful

\section{Disciplines}

Arts and Humanities | Life Sciences | Medicine and Health Sciences | Social and Behavioral Sciences

\section{Publication Details}

Hebden, L., King, L., Kelly, B. P., Chapman, K., Innes-Hughes, C. \& Gunatillaka, N. 2010, 'Regulating the types of foods and beverages marketed to Australian children: how useful are food industry commitments?', Nutrition and Dietetics, vol. 67, no. 4, pp. 258-266.

Authors

L Hebden, Lesley King, Bridget P. Kelly, Kathy Chapman, Christine Innes-Hughes, and Nilakshi Gunatillaka 


\title{
INSIGHT
}

\section{Regulating the types of foods and beverages marketed to Australian children: How useful are food industry commitments?}

\author{
Lana HEBDEN, ${ }^{1}$ Lesley KING,' Bridget KELLY,' Kathy CHAPMAN, ${ }^{2}$ Christine INNES-HUGHES ${ }^{1,2}$ and \\ Nilakshi GUNATILLAKA' \\ 'Prevention Research Collaboration, University of Sydney, Camperdown, and ${ }^{2}$ Cancer Council NSW, \\ Woolloomooloo, New South Wales, Australia
}

\begin{abstract}
Aim: Any regulation of food marketing to children requires clear definitions of the types of foods considered inappropriate and subject to restrictions. The aim of this research was to examine the commitments made by signatory companies of the Australian Food and Grocery Council's Responsible Marketing to Children Initiative regarding the types of foods considered appropriate for marketing to children.

Methods: Nutrient criteria developed by signatory food companies were examined by comparing (i) thresholds set for negative nutrients (saturated fats, added sugars and sodium) and total energy to two existing nutrient criteria: Healthy Kids Association and the National Heart Foundation Tick, and (ii) the types of foods considered appropriate for marketing to children, if applying companies' commitments or the product's nutrient profile using the Food Standards Australia and New Zealand nutrient profiling tool.

Results: All five company-developed nutrient criteria examined specified higher thresholds for negative nutrients compared with existing criteria, and were more likely to report negative nutrients per serve rather than per $100 \mathrm{~g}$. When applying company commitments, 57\% more energy-dense, nutrient-poor foods and beverages were considered appropriate for marketing to children, compared with nutrient profiling.

Conclusion: Food industry commitments regarding the types of foods considered appropriate for marketing to children do not adequately restrict the marketing for energy-dense, nutrient-poor foods. It is recommended food manufacturers who commit to restricting their marketing of unhealthy foods to children use a standardised, independent nutrient profiling tool based on per $100 \mathrm{~g} / 100 \mathrm{~mL}$ to determine the appropriateness of foods and beverages for marketing to children.
\end{abstract}

Key words: children, food composition, food marketing, nutrient profiling, policy, self-regulation.

\section{Introduction}

Australian children continue to consume an excess amount of energy-dense, nutrient-poor (EDNP) or 'extra' foods. ${ }^{1}$ The

L Hebden, BND, Research Dietitian

L King M Psychology (Hons), Executive Officer, PANORG and Conjoint Senior Lecturer, School of Public Health

B. Kelly, MPH, BSc. (Nutrition) Hons, PhD candidate

K. Chapman, M Nutr \& Diet, Nutrition Program Manager

C. Innes-Hughes, BSc, (Hons) Grad Dip, Nutr. \& Dietetics, Grad Cert

Diabetes Education \& Management (MPH due for completion June 2010) Public Healıh Nutulion Research Officer

N. Gunatillaka, BSc, (Nutrition) Hons, Research Assistant

Correspondence: L. Hebden, Prevention Research Collaboration,

University of Sydney, Level 2 Medical Foundation Building,

Camperdown, NSW 2050, Australia. Email:

lanahebden@sydneyedu.au

Accepted August 2010 heavy marketing of these foods to children is recognised as one factor contributing to this excess intake, and there is increasing research and attention on how to curb food marketing to children ${ }^{2-6}$

The term 'food marketing' includes the promotion of food products, with television advertising forming the main medium reaching children. ${ }^{2}$ Any policy restrictions on the marketing of foods and beverages to children require clear definitions of the types of foods that are considered inappropriate and subject to restriction, whether these are in the form of statutory regulations, non-statutory government guidelines or industry sell-regulatory policies.,7-9 For example, the UK government food marketing regulations use a specific system of nutrient profiling, which calegorises foods according to their nutritional composition. ${ }^{10}$ By contrast, industry self-regulatory initiatives to date have not provided such precise specifications regarding the types of foods subject to restriction. ${ }^{11-13}$ 
In January 2009, the Australian Food and Grocery Council (AFGC) introduced a national self-regulatory initiative on responsible marketing to children. " Food companies who become signatories of this initiative must publish an action plan detailing their commitments to restricting their advertising for less healthy foods to children. The AFGC stipulated that signatory lood companies must not advertise foods to children that do not '... represent healthy dietary choices, consistent with established scientific or Australian government standards', ${ }^{11}$ thus permitting companies to determine their own criteria.

The aim of this research was to examine AFGC signatory companies' commitments regarding the types of foods they consider inappropriate for advertising to children and therefore subject to food marketing restrictions.

\section{Methods}

By the end of 2009, 16 food companies had become signatories, with published action plans (Table 1). An examination o[ companies' interpretations of 'healthy dietary choices' found that while some companies did not include any definition for 'healthy dietary choices', others nominated existing nutrient criteria (including those developed by the Healthy Kids Association and the National Heart Foundation) ${ }^{14,15}$ national dietary guides or developed their own nutrient criteria. Companies that developed and published their own nutrient criteria (Cereal Partners Worldwide, Fonterra, Kellogg's, Kraft, and Nestlé) were analysed by comparing the company-specified threshold levels for energy, saturated fat, added sugars and sodium to each other, as well as to two existing sets of criteria referred to by some signatory food companies for indicative comparison: the Healthy Kids Association nutrient criteria for green and amber foods ${ }^{14}$ and the Tick criteria developed by the National Heart Foundation. ${ }^{15}$

Food calegories assessed in the present study (dairy products, breakfast cereals and snack foods) comprised those for which nutrient thresholds were available from all companies' nutrient criteria analysed for the purpose of comparison, and those contributing a substantial proportion of children's total daily energy intake. ${ }^{16}$ Where possible, nutrient thresholds set by signatory companies were further analysed for their contribution to daily nutrient reference values for children $4-13$ years. ${ }^{17}$

A sample of 52 unique food and beverage products manufactured by AFGC signatory companies were then assessed for their appropriateness for marketing to children if applying companies' commitments to only advertise 'healthy dietary choices' or the product's nutrient profile using the Food Standards Australia New Zealand (FSANZ) nutrient profiling tool ${ }^{18}$ The FSANZ tool has been proposed for use in determining the appropriateness of foods to carry health claims, and was based on a nutrient profiling tool developed for the UK Food Standards Agency, developed specifically for the purpose of regulating the types of foods marketed to children on UK television. ${ }^{10}$ The FSANZ tool differs from the UK version in allowing higher scores lor energy, saturated fal and sodium for fats, oils and cheeses to reflect the typical nutritional composition of these foods, and has been tested with over 10,000 foods from Australian and New Zealand lood composition databases.

Sampled products were sourced from: (i) products marketed on children's most popular Internet websites during July 2009; and (ii) products advertised on Sydney free-to-air television during May 2009. During these advertising periods, one signatory company (Patties) did not advertise their products, thus this company was excluded from this part of the analysis. Details on the data collection and coding methods are described elsewhere. ${ }^{19,20}$

\section{Results}

A summary of the nutrient criteria nominated by AFGC signatory companies to assess whether their products represent 'healthy dietary choices' is provided in Table 1. Seven companies developed their own criteria, lour used existing nutrient criteria or guidelines and four companies provided no definition for 'healthy dietary choices' (Table 1). Of the seven companies that developed their own criteria, two were not publicly available for analysis. Thus five sets of company-developed nutrient criteria were analysed,

Cereal Partners Worldwide and Fonterra stated nutrient thresholds per $100 \mathrm{~g} / 100 \mathrm{~mL}$ or as per serve, for both positive (i.e. thiamin, iron and calcium) and negative nutrients (i.e. saturated fat and sodium), while Kellogg's set thresholds for negative nutrients only and reported these per serve (Table 1). Nestlés nutrient profiling system set thresholds for negative and positive nutrients as a proportion of a daily reference value, with daily reference values based on $\therefore$. WHO and/or other worldwide recognised guidelines on nutrient intake from health authorities' reported per serve for 4-8 and 9-11 year olds. ${ }^{21}$ Kraft Sensible Solutions also used a daily value measure based on '... the 2005 U.S. Dietary Guidelines, as well as authoritative statements from the U.S. Food \& Drug Administration, National Academy of Sciences, and other public health authorities' and only required products meet at least one criterion for negative or positive nutrients. ${ }^{22}$

Thresholds set for energy and negative nutrients (salurated fat, added sugar and sodium) differed for companydeveloped and existing nutrient criteria.

\section{Saturated fats}

Figure 1 presents company-developed and Healthy Kids thresholds for saturated fat for dairy products. Fonterra's crileria were consistent with Healthy Kids saturated fat thresholds for dairy products per $100 \mathrm{~g}$, apart from dairy desserts where $30 \%$ more saturated fat per $100 \mathrm{~g}$ was permitted. Nestlé set higher thresholds for saturated fat for dairy products and reported these per serve, where a serve varied between $70 \mathrm{~g}$ and $200 \mathrm{~g}$.

One serve of a dairy product containing $4 \mathrm{~g}$ saturated fat could contribute $16-25 \%$ of the recommended limit for saturated fat for children to reduce chronic disease risk 

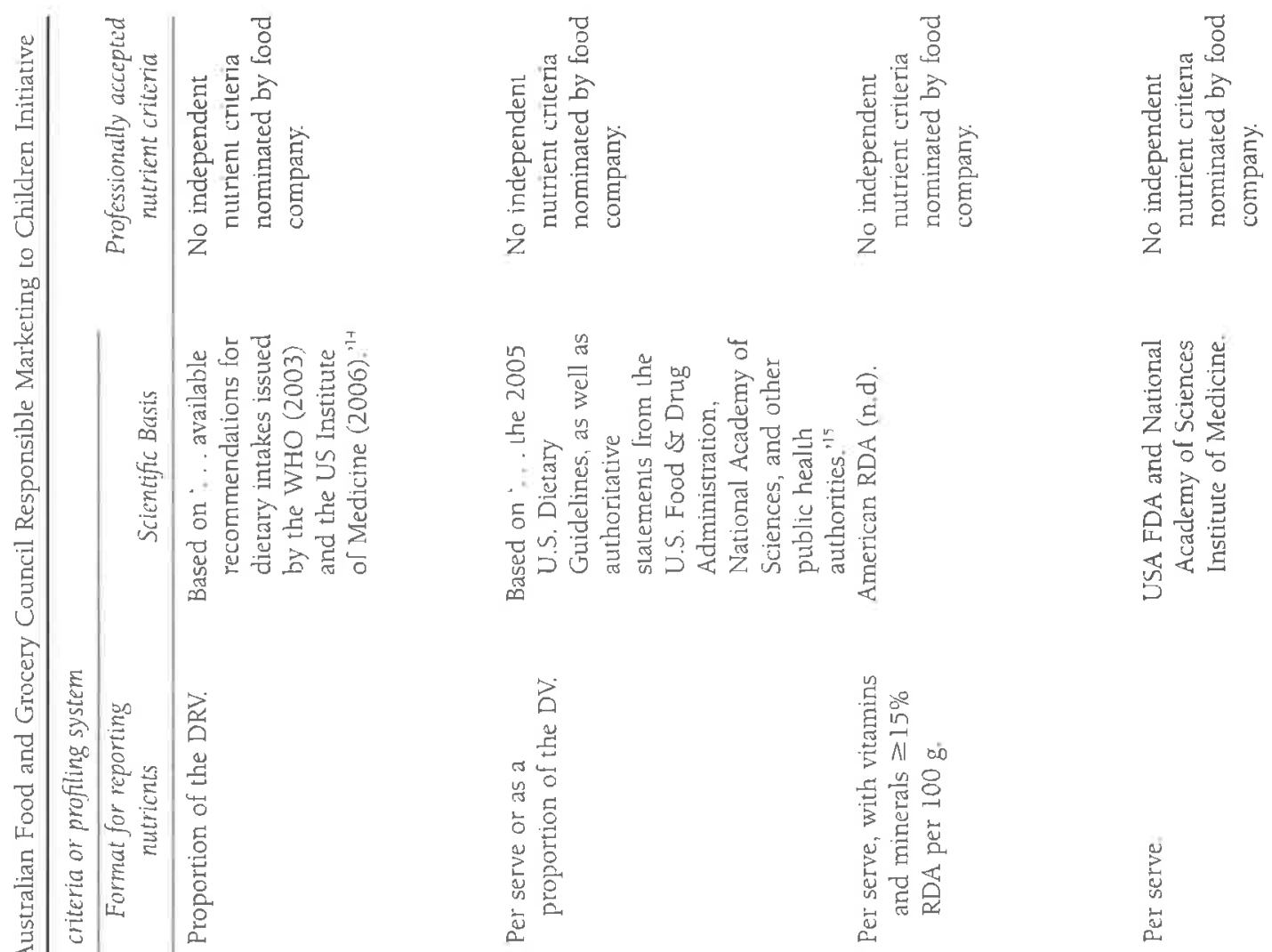

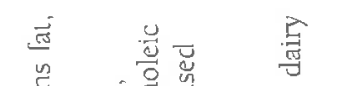

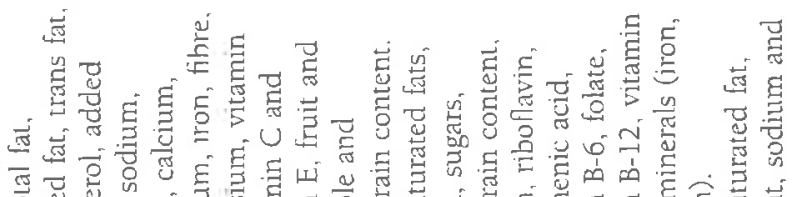

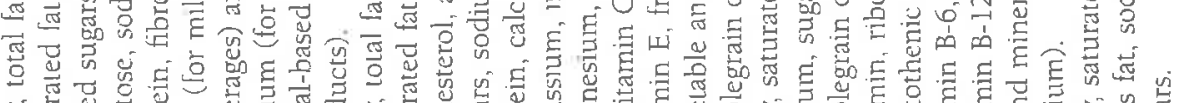

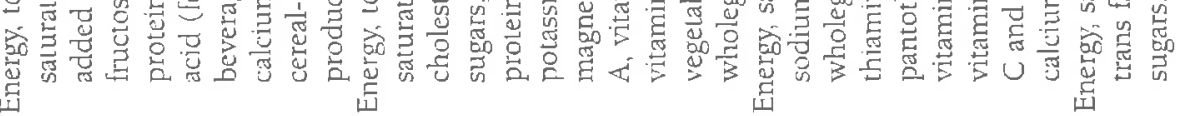

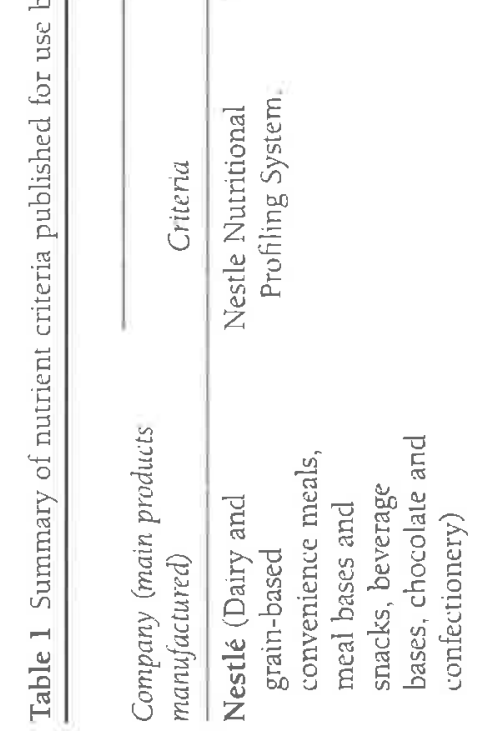

260
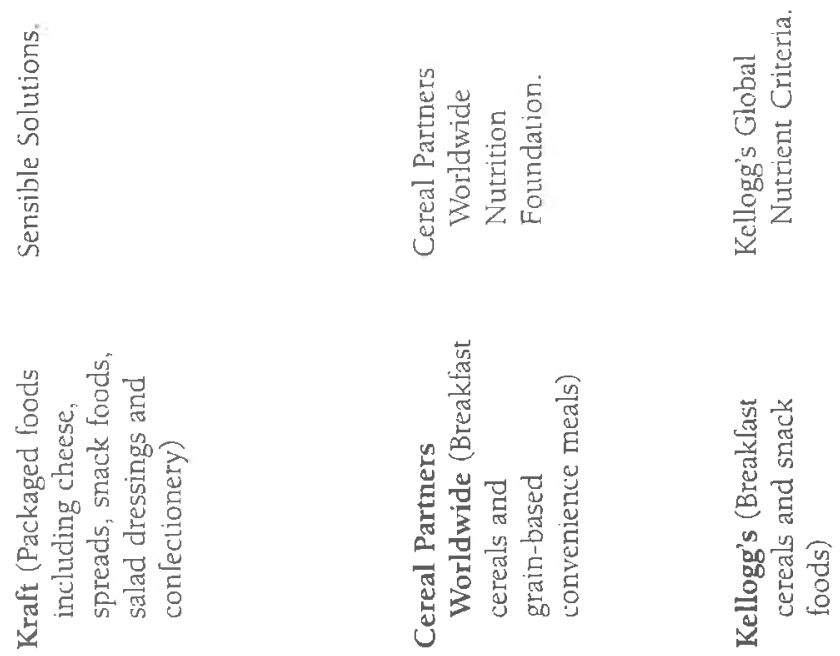

(C) 2010 The Authors Nutrition \& Dietetics (c) 2010 Dietitians Association of Australia 

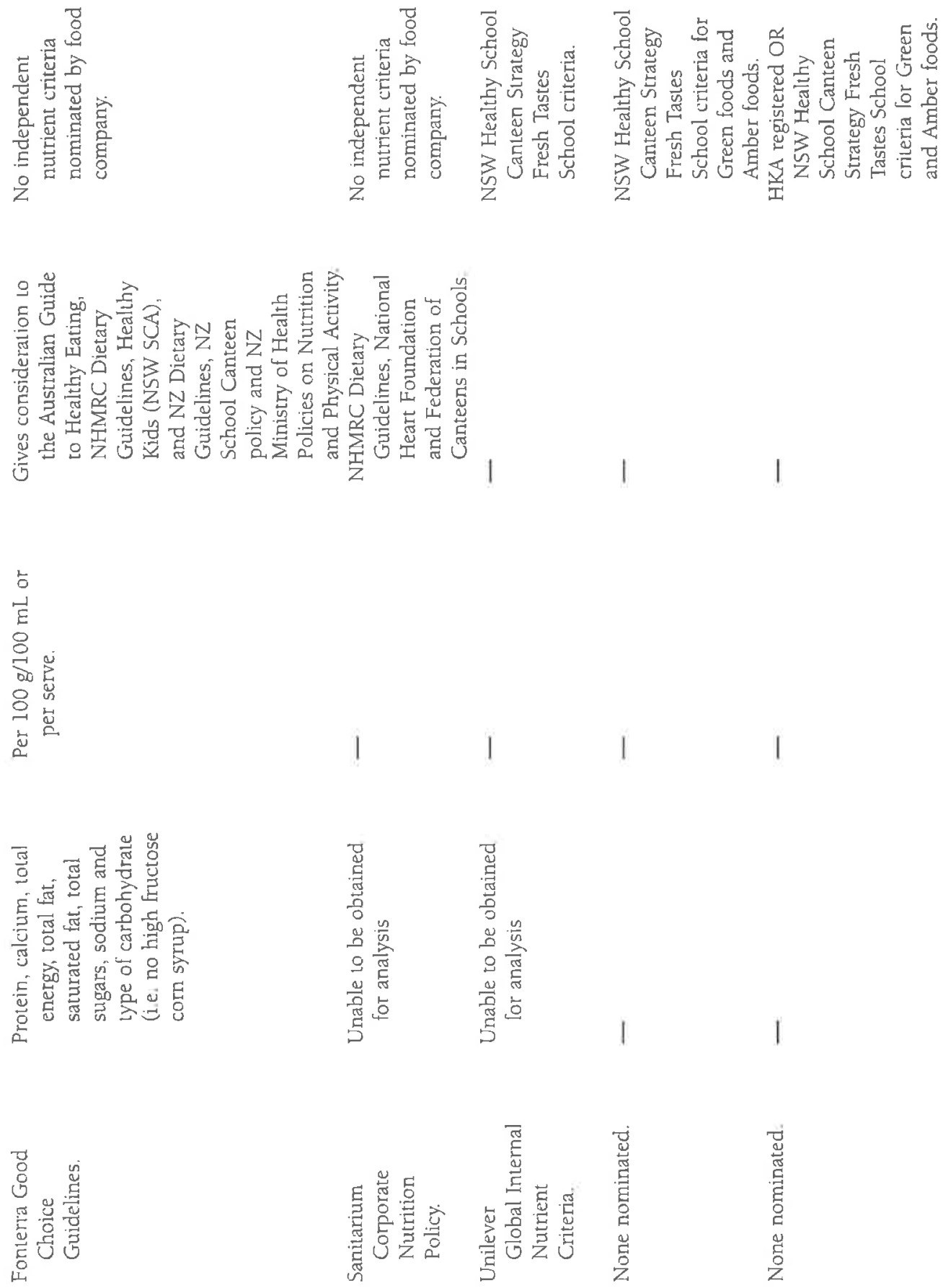

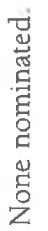
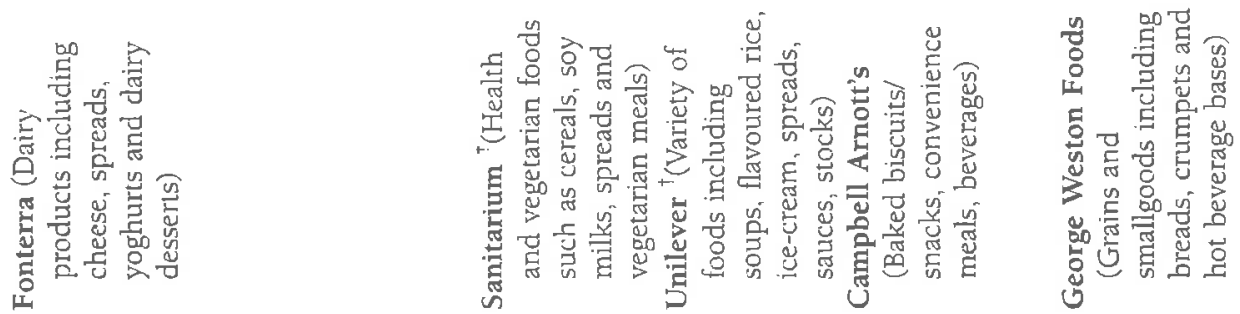


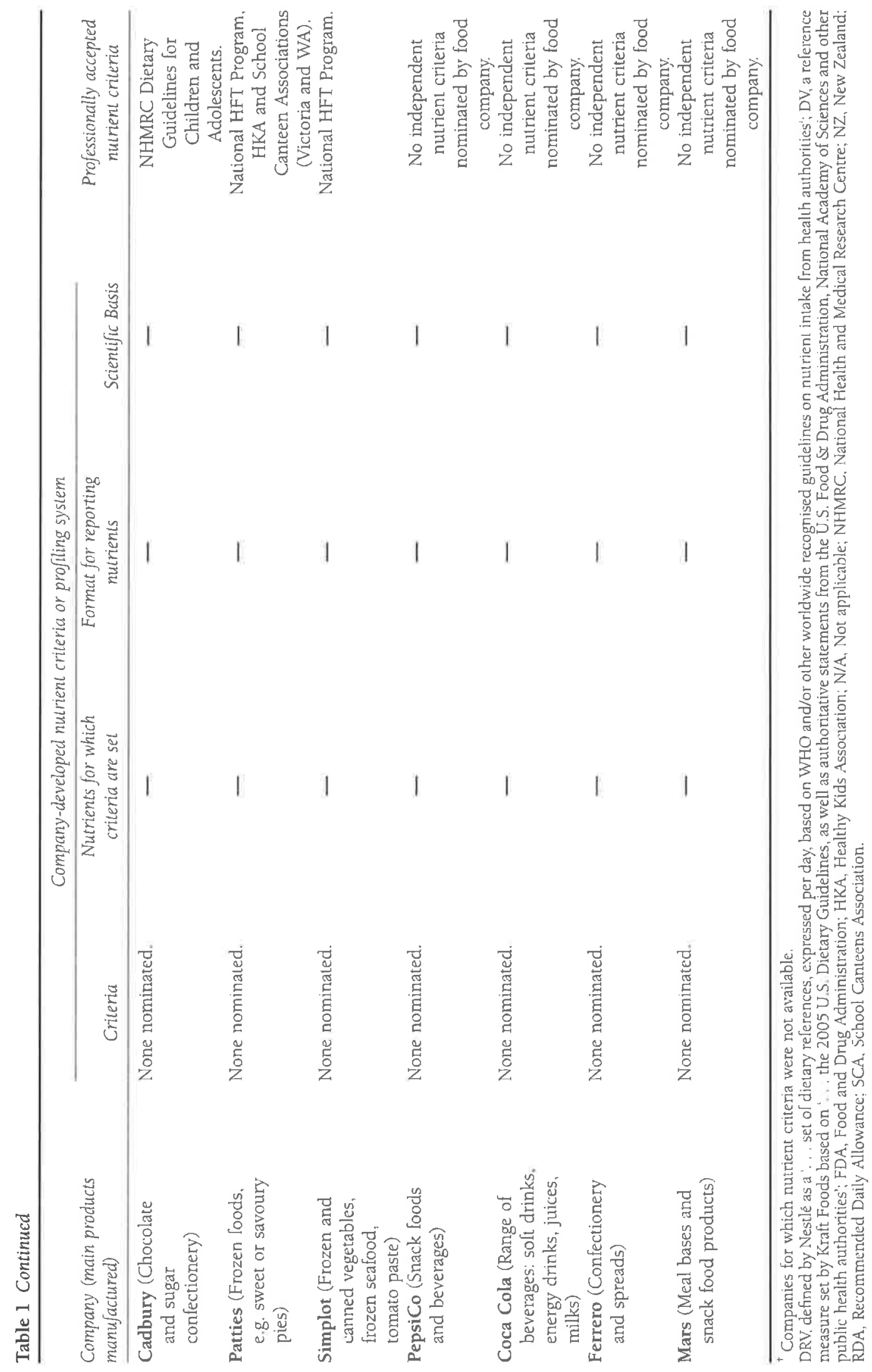




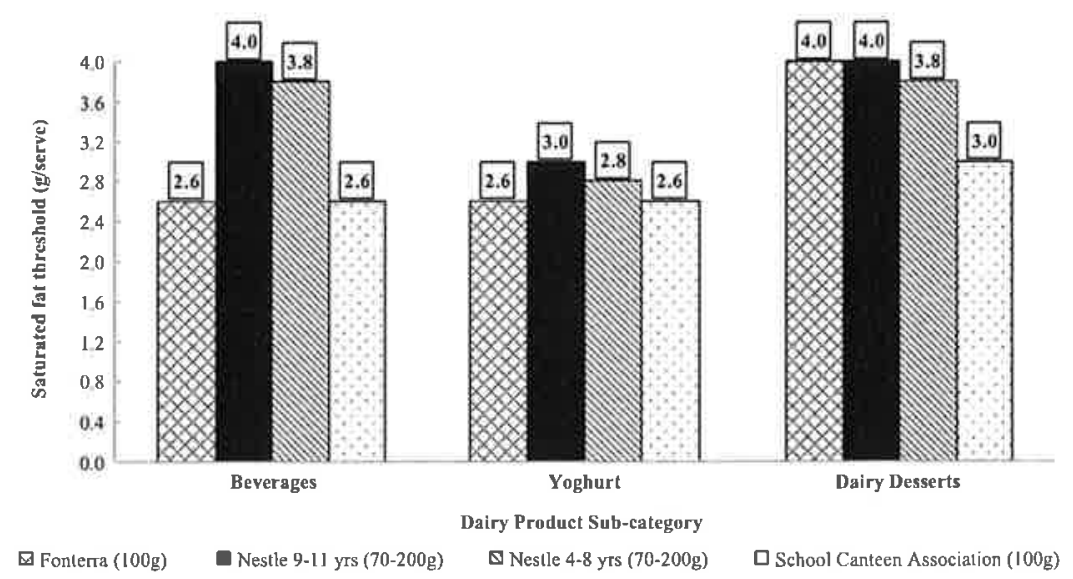

Figure 1 Comparison of saturated fat thresholds set by the NSW School Canteen Association Healthy Kids nutrient criteria and by signatory companies (Fonterra and Nestlé) for dairy foods, as grams per serve.

(16-25 g for 6-12 year olds; based on 10\% of the estimated energy requirement (EER) with physical activity level (PAL) 1.6), ${ }^{17}$ assuming children are physically active and only one serving was consumed each day.

\section{Energy}

Company-developed nutrient criteria allowed higher thresholds for the energy content of snack foods per serve compared with existing criteria. While both the Healthy Kids and the Tick criteria allowed $\leq 600 \mathrm{~kJ}$ per serve for a snack food, AFGC signatory companies allowed up to $840 \mathrm{~kJ}$ per serve.

Based on the higher thresholds set by Cereal Partners Worldwide, Kellogg's and Nestlé, a single serve of snack food marketed by these companies could provide $9-14 \%$ of a physically active child's EER (based on PAL 1.6), compared with $6-10 \%$ if a $\leq 600 \mathrm{~kJ}$ threshold were used. ${ }^{17}$ It is worth noting that the portion size of snack foods manufactured by these companies varied from 17 to $37 \mathrm{~g}$, permitting wide variability in the energy density ( $\mathrm{kJ} / \mathrm{g}$ weight) of these snack foods.

\section{Sodium}

The Healthy Kids nutrient criteria permit 113 mg of sodium per serve of snack food. Compared with the Healthy Kids threshold, Cereal Partners Worldwide allowed up to $77 \%$ more sodium, while Kellogg's and Nestlé allowed up to 104 and $177 \%$ more sodium, respectively.

\section{Added sugar}

The Healthy Kids and Tick criteria do not specify a threshold for the sugar content of breakfast cereals. ${ }^{14,15}$ Alternately, Kellogg's and Nestlé applied thresholds for added sugars of $12 \mathrm{~g}$ and $25 \mathrm{~g}$ per serve of breakfast cereal, respectively.

The Nestle Nutritional Profiling System specified their threshold for added sugars as $\leq 25 \%$ of the total energy content of the cereal per serve. According to the Nestlé
Nutritional Profiling System a serve of breakfast cereal may contribute up to $20 \%$ of the total daily energy relerence value for children. This equals up to $400 \mathrm{kcal}$ for children 9-13 years. Thus, per serve of breaklast cereal, up to $25 \mathrm{~g}$ of added sugars may be permitted $(400 \mathrm{kcal} / 0.25=100 \mathrm{kcal}$; $100 \mathrm{kcal} / 4=25 \mathrm{~g}$; based on $4 \mathrm{kcal}$ per gram for carbohydrates).

To place these figures in context, a 30 -g serve of vestlé breaklast cereal containing $25 \mathrm{~g}$ of added sugar may contribute up to $4-7 \%$ of a physically active child's EER (PAL 1.6) from added sugars alone. ${ }^{17}$ Given it is recommended children consume no more than $10 \%$ of their total daily EER from added sugars, ${ }^{23}$ one 30 -g serve of breakfast cereal can provide the majority of this recommendation for physically active children. Note that no Nestlé breakfast cereals contain $100 \mathrm{kcal}$ per serve and hence breakfast cereals appealing to children such as Milo Duo, Milo and Nesquik cereals all contain less than 10 grams total sugar per $30 \mathrm{~g}$ serve. Although, these cereals do contain more than $30 \%$ total sugar, derived largely from added sugars, and according to the Nestlé Nutritional Profiling System are eligible for marketing to children.

\section{Assessment of product eligibility for marketing to children}

Figure 2a illustrates the proportion of AFGC signatory company products assessed as appropriate lor marketing to children, using the FSANZ nutrient profiling tool. Overall, $38 \%(20 / 52)$ of products were assessed as appropriate, with higher proportions of low sugar/high fibre brcakfast cereals $(80 \% ; n=8)$, dairy products $(50 \% ; n=6)$ and core combined meals (e.g. Crozen meals $<10 \mathrm{~g}$ lat per serve; $100 \%$; $=2$ ) assessed as appropriate. Inappropriate products mostly comprised chocolate, confectionery, cakes, muffins, sweet biscuits, pies, pastries, ice-cream and snack foods (Figure 2a).

Using company-developed nutrient criteria (Figure 2b), $83 \%(43 / 52)$ of products were assessed as appropriate for marketing to children, with $57 \%$ more EDNP foods assessed 
L, Hebden et al.
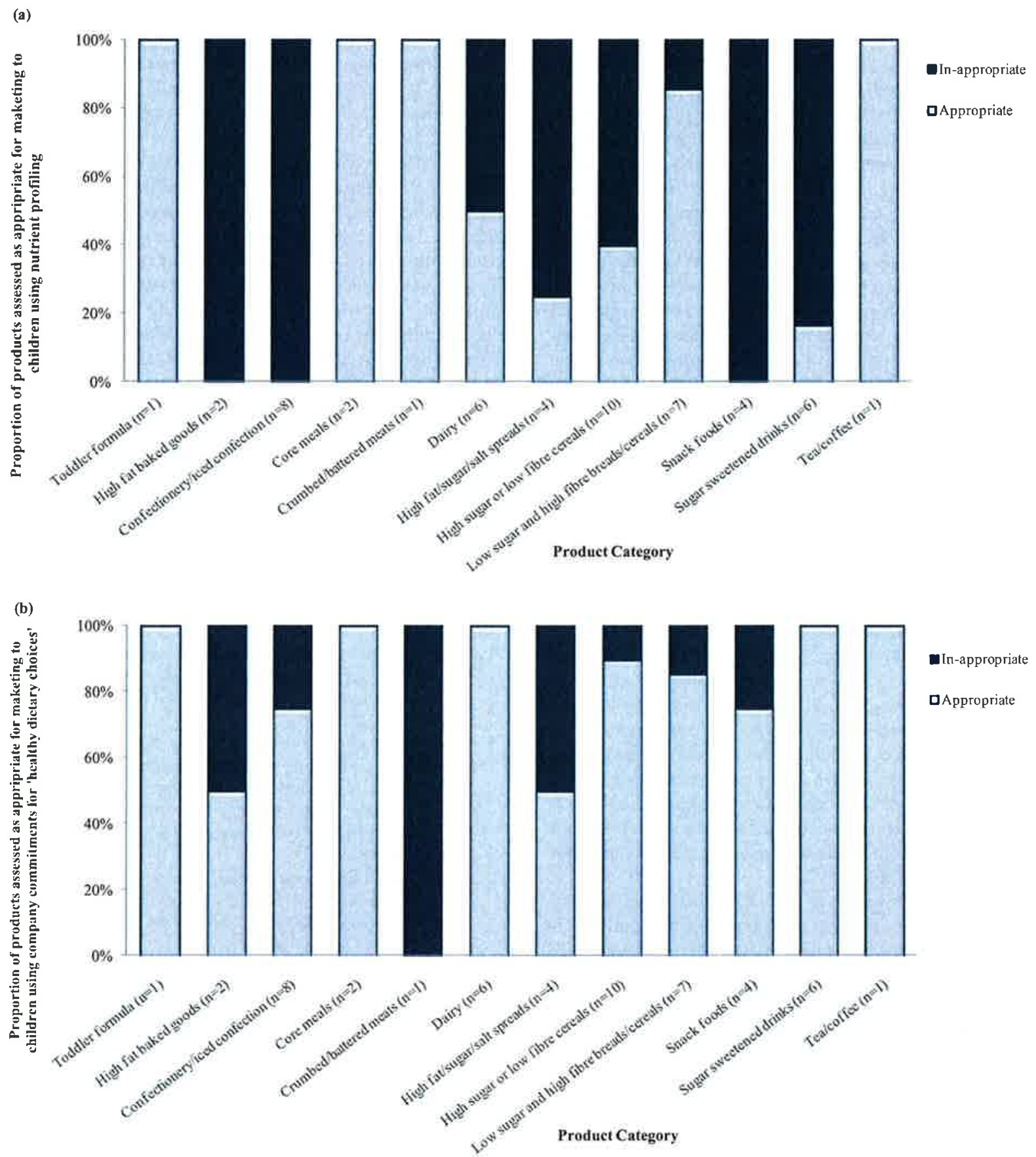

Figure 2 Proportion of the product sample* $(n=52)$ assessed as appropriate for marketing to children using (i) nutrient profiling and (11) company commiments to marker 'healthy dietary choices', by food category *Sampled products advertised and manufactured by companies that did not specily criteria for determining which of their products are 'healthy dietary choices' were assessed as appropriate, as all their manufactured producls would be appropriate for marketing to children where no regulatory criteria are specificd.

as appropriate when compared with the FSANZ tool (77\% vs 20\%). Differences between company-developed criteria and the FSANZ tool, were most notable for chocolate/ confectionery and ice-cream/iced confection with $86 \%$ more products assessed as appropriate for marketing to children compared with the FSANZ tool, followed by snack loods $(75 \%)$, sugar sweetened beverages $(67 \%)$ and baked goods (cakes, muffins, sweet biscuits, pies, pastries; $50 \%$ ) 


\section{Discussion}

The present study found that of the five AFGC signatory company-developed nutrient criteria available for analysis, all varied considerably between companies and were generally more lenient than existing nutrient criteria used by Australian government and non-government organisations for the mutritional classification of foods. This variability makes it complex to monitor each company's compliance with their specified criteria. The commitments made by AFGC signatory companies to only market 'healthy dietary choices' to children permit the majority of their products, comprising a high proportion of EDNP foods, to be marketed to children. This undermines the potential effectiveness of these self-regulatory policies and brings into question industry motivations for developing responsible marketing plans.

A further issue identificd was that while many companies reported nutrient thresholds on a per serve basis, the lack of standardised serving sizes within Australia introduces wide variability in the interpretation and application of nutrient criteria and diminishes the effectiveness of such thresholds as indicators of nutritional composition. For example, if a 200-mL serve size of llavoured milk is used to report nutrients per serve, this allows three times less added sugar, saturated fat and total energy to be reported than what would be in the amount 'as consumed' from a $600-\mathrm{mL}$ portion size

Thus, in their current form, the nutrient criteria developed by food companies as the basis for regulating the types of foods marketed to children do not adequately protect children from the negative effects of advertising for EDNP foods on their dietary behaviours and intake; of which, Australian children currently exceed recommended limits for sodium and a minority meet dietary guidelines for sugar and saturated fat intake. ${ }^{16,24}$

The findings suggest that any regulation of food marketing to children requires consistent nutrient criteria to determine which foods and beverages are considered inappropriate. One limitation, both for the present study as well as the AFGC Initiative itself, was that Unilever's Global Internal Nutrient Criteria and Sanitarium's Corporate Nutrition Policy were not publicly available. It is also recognised that the existing nutrient criteria used in the present study have been developed for different purposes, with the Healthy Kids criteria being designed to guide what foods may be sold to children within school canteens and the Tick criteria for guiding consumer choices towards selecting healthier food products, and not necessarily in guiding the types of foods considered appropriate for marketing to children. Alternatively, the FSANZ nutrient profiling tool potentially provides a suitable basis for identifying foods appropriate for marketing to children, being closely based on the UK nutrient profiling system developed to underpin food marketing restrictions in the UK and tested successfully in New Zealand, to identify high fat, salt or sugar foods marketed on television. ${ }^{10,25}$ The FSANZ tool is also consistent with the body of evidence regarding nutrient profiling systems that recommend consideration of both negative nutrients (total energy, saturated lat, added sugar, sodium) and positive nutrients (dietary fibre, essential vitamins/ minerals, fruit, vegetable and wholegrain content) and assessing these nutrients within foods/beverages per $100 \mathrm{~g}$ or $100 \mathrm{~mL} .{ }^{26,27}$

Thus, it is recommended a single nationally accepled nutrient profiling tool is used to clearly define the types of foods and beverages considered appropriate for marketing to children. This recommendation is consistent with recommendations of the World Health Organization recommending any policies for regulating food marketing to children provide :. clear definitions of the policy components. ${ }^{15}$ This includes clear definition of the type of foods permitced for marketing to children. If food and beverage companies are unable or unwilling to conform to a single, scientifically based and professimally delensible nutrient profiling tool that effectively discriminates EDNP foods, then it remains for government to provide this component of a regulatory framework. ${ }^{5}$ Further research is required to evaluate the FSANZ nutrient profiling tool with a larger product sample to test its feasibility for regulating what loods are appropriate and inappropriate for marketing to children.

\section{References}

1 Kwan J, Rangan A, Louie J. Consumption of 'extra' foods by Australian children: 2007 children's survey results. Australian and New Zealand Obesity Society 17th Amual Sctentific Meeting. October 2009.

2 Cairns $G$, Angus K, Hastings G. The Extent, Nature and Effects of Food Promotion to Children: A Review of the Evidence to December 2008. Institute of Social Marketing, University of Stirling \& Open University, 2009. (Available from: http:/www.who.int/ dietphysicalactivity/Evidence_Update_2009.pdf, accessed 18 February 2010)

3 World Health Organization. Global Strategy on Dier Physical Activity and Health; 2004; (Available from: http://www.who.ind dietphysicalactivity/strategy/eb11344/strategy_english_web pdf, accessed 14 January 2010).

4 National Preventative Health Taskforce. Australia: The Healthiest Country by 2020. National Preventative Health Strategy--The Roadmap for Action. Canberra, ACT: Commonwealth of Australia, 2009; (Available from: http:/www.health govau/internet/ preventativehealth/publishing, ns//Content/nphs-roadmap, accessed 18 February 2010)

5 World Health Organisation. Prevention and control of noncommunicable diseases: implementation of the global strategy, Report by the Secretariat. Sixty-third World Health Assembly. Paper A63/12. Geneva; April 2010. (Available from: http:// apps who int/gb/ebwha/pdf_files/EB126/B126_12-en pdf. accessed 31 May 2010).

6 Swinburn B, Sacks G, Lobstein T et al. Sydney Principles' for reducing the commercial promotion of foods and beverages to children. Public Health Nutr 2008; 11(9): 881-6.

7 Hawkes C Regulating and litigating in the public interest: regulating food marketing to young people worldwide: trends and policy drivers. Am J Public Health 2007; 97: 1962-73.

8 Handlsey E, Mehta K, Coveney J, Nehmy C. Regulatory axes on food advertising to children on television Aust N Z Health Policy $2009 ; 6: 1-10$ 
9 Mackay S. Food advertising and obesity in Australia: to what extent can self-regulation protect the interests of children? Monash Univ Law Rev 2009; 35: 118-46.

10 Rayner M, Scarborough P, Stockley L, Nutrient Profiles: Options for Definitions for Use in Relation to Food Promotion and Children's Diets. London: British Heart Foundation Health Promotion Research Group, Department of Public Health, University of Oxford, 2004; (Available from: http://www.food.gov.uk/ multimedia/pdfs/nutricntprofilingfullnepoit pdf, accessed 14 January 2010).

11 Australian Food and Grocery Council. The responsible children's marketing initiative, Barton, ACI; 2009. (Available from: http:/www.afgc org.au/industry-codes/advertising-kids.html, accessed 15 December 2009).

12 Australian Association of National Advertisers (AANA). Australian quick service restaurant industry initiative for responsible advertising and marketing to children, August 2009. (Available from: http:/wwwaana.com au/documents/QSRAInitiativefor ResponsibleAdvertisingandMarketingtoChildrenJune 2009.pdf, accessed 1 September 2009).

13 Council of Better Business Bureaus Inc Children's food and beverage advertising initiative program and core principles statement (Effective January 1, 2010). 2009. (Available from: http://www.bbb.org/us/storage/0/Shared\%20Documents/ Core\%20Principles\%20Final\%20Letterhead\%2012-2-09.pdf, accessed 23 February 2010).

14 Healthy Kids Association. Nutrient Criteria for the Registration of Food and Beverage Products for NSW School Canteens. Epping, NSW: New South Wales School Canteen Association Inc, 2005. (Available from: http://wwwbbb.org/us/storage/0/Shared\%20 Documents/Core\%20Principles\%20Final\%20Letterhead\%20 12-2-09.pdf, accessed 22 October 2010)

15 National Heart Foundation of Australia Tick criteria 2009. (Available from: http://wwwheartfoundation org au/sites/tick/ Health_Professionals/Pages/TickCriteria.aspx, accessed 23 December 2010).

16 Commonwealth Government of Australia, 2007 Australian National Children's Nutrition and Physical Activity Survey -maun futdings Commonwealth of Australia: 2008 (Availablc from: http://www.health govau/internet/main/publishing.ns// Content/66596E8FC68FD1A3CA2574D50027DB86/\$File/ childrens-nut-phys-survey.pdf, accessed 8 February 2010).

17 Commonwealth Department of Health and Ageing Australia and Ministry of Health New Zealand. Nutrient Reference Values for Australia and New Zealand Including Recommended Dietary Intakes Canberra: Commonwealth of Australia, 2006.

18 Food Standards Australia and New Zealand. Health claims nutrient profiling calculator lonline calculatorl 2009 (Available from: http://www foodstandards govau/ consumerinformation/labellingoffood/ mutritionhealthandrelatedclaims/nutrientprofilngcal $3499 \mathrm{~cm}$, accessed 17 December 2009),

19 Kelly B, Smith B, King L, Flood V, Bauman A. Television food advertising to children: the extent and nature of exposure. Public Health Nutr 2007; 10: 1234-40.

20 Kelly B, Bochynska K, Kornman K, Chapman K. Internet food marketing on popular children's websites and food product websites in Australia. Public Health Nutr 2008; 11: 1180-87.

21 Nestlé. The Nestlè Nutritional Profiling System, Its Product Categories and Sets of Criteria. Vevey, Switzerland: Nestec Ltd, 2009. (Available from: http://www.research nestle com/NR/rdonlyres/ D70A5C47-0BC8-4B02-A65D-7CDB846497D8/0/ NutritionalProfilingJableFIN $A]$. pdI, accessed 17 Deccmber 2009).

22 Kraft Foods Global Inc Sensible solutions nutrition criteria, 2009, (Available from: http://stg64,kraftrecipes, com/kl/ HealthyLiving/SensibleSolution/nutritioncriteria aspx, accessed 17 December 2009).

23 World Health Organization. Diet, nutrition and the prevention of chronic diseases, 2003, (Available from: http:// whqlibdoc, who.int/trs/WHO_TRS_916_pdf, accessed 8 February 2010).

24 National Health and Medical Research Council Dietary Guidelines for Children and Adolescents in Australia Incorporating the Infant Feeding Guidelines for Health Workers Canberra, ACT: Commonwealth of Australia, 2003; (Available from: http:// www nhnurc goval_filcs_nhmurdfile/publications/synopses/ n34.pdf, accessed 18 May 2010).

25 Jenkin $G$, Wilson N, Hermanson N. Indentifying 'unhealthy' food advertising on television: a case study applying the UK Nutrient Profile model Public Health Nutr 2008; 12: 614-23.

20 Drewnowski A. Nallot M, Darmon N Should nutrient profiles be based on $100 \mathrm{~g}, 100 \mathrm{kcal}$ or serving size? Eur J Clin Nutr 2009; 63: 898-904.

27 Arambepola C, Scarborough P, Rayner M. Validating a nutrient profile model Public Health Nutr 2007; 11: 371-8. 
